structured approach to the history and examinations of a child with possible tic disorder and when investigations are indicated. Management is discussed under two categories of (a) Simple tics and (b) Tics with co-morbidities. Advice is given on who will benefit from psychology input and what to do when co-morbidities are noted. Indications for paediatric neurology and CAHMS referral are discussed. The Appendix includes community referral forms, the Yale tic questionnaire and some links to information for carers.

Conclusion The authors are hopeful this guideline has fulfilled the aims outlined. Consideration will be given to seeking feedback from users when it is formally adopted. Paediatricians from other Trusts may also find much of the guidance helpful though caution would be needed with the referral pathways which are different in different Trusts.

\section{P149 IS VIRTUAL THE FUTURE OF OPD?}

Attia Kalim*, Suzanne Kelleher, Jean Donnelly. Our Lady's Children's Hospital Crumlin, Dublin, Ireland

\subsection{6/archdischild-2019-epa.504}

Introduction The General Paediatric Outpatients Department at Our Lady's Children's Hospital Crumlin has a greater than two year waiting list for new routine appointments. Long waiting time is considered as one of the most concerning matters in the majority of health care organisations ${ }^{1}$. A wait time of no more than 6 months for routine appointments is proposed $^{2}$. A virtual clinic was run by three General paediatricians from November 2017 to October 2018, with the aim to reassess and prioritise the 'long-waiters' on the waiting list. A Virtual clinic is a contact between the clinical team and the patient, without a face to face meeting, to plan clinical care with the use of telecommunication ${ }^{3}$.

Methods Parents of the longest waiting children were called by the paediatricians, after going through their referral letters. If parents were not contactable, their GPs were contacted. Progression of the symptoms, persistent concerns, any reviews in the meantime were recorded. Subsequently patients were either removed from the list with parental consent or remained on the list with or without prioritisation.

Results A total of 65 patients were reviewed via virtual clinics. 43 patients were subsequently removed from the list with parental consent. In $15(23 \%)$ referring reason was resolved, $4(6 \%)$ were seen by other hospitals and $2(3 \%)$ were seen privately, while $7(11 \%)$ were reviewed by other specialities. 22 patients remained on the waiting list. Among these 65, 41 $(63 \%)$ parents were contactable, GPs were contacted in 9 (14\%) cases while no one was contactable in 15 (23\%) cases. Most common referral diagnoses were developmental concerns and gastrointestinal issues including abdominal pain, constipation and reflux, each contributing to $30 \%$ of the cohort. $10 \%$ were referred for recurrent UTIs, 3\% with respiratory symptoms, $8 \%$ with seizures and headaches, while $18 \%$ were miscellaneous including eczema and fatigue.

Conclusion Virtual clinics can play an important role in dealing with the long waiting lists in paediatric population.

\section{REFERENCES}

1. British Columbia Medical Association (2006). Waiting too long: Reducing and Better Managing Wait Times in BC: A policy Paper by the BCMA's Council on health Economics and Policy. London: BCMA.
2. Department of Health. Choice At Six Months: Good Practice. London: DoH, 2005

3. Currell R, Urquhart C, Wainwright P, Lewis R. (2000) Telemedicine versus face to face patient care: effects on professional practice and health care outcomes. Cochrane Database Syst Rev. (2): CD002098. https://doi.org/10.1002/14651858. CD002098 PMID: 10796678

\section{P150 PRIME (PRETERM INFANTS NEED MILK EARLY); A QUALITY IMPROVEMENT INITIATIVE IN A TERTIARY NEONATAL UNIT}

Emma Dunne*, Madeleine Murphy, Roberta McCarthy, Lorraine O'Hagan, Helen Batson, Anna Curley. National Maternity Hospital, Dublin, Ireland

\subsection{6/archdischild-2019-epa.505}

Aim Maternal milk (MM) protects against necrotizing enterocolitis and sepsis. PRIME is a multi-disciplinary initiative to improve the early provision of $\mathrm{MM}$ for preterm infants and enhance outcomes. Our aim was to increase the number of high-risk infants receiving $\mathrm{MM}$ in the first day life in our tertiary neonatal unit.

Method We retrospectively reviewed time to first MM for infants born $<32$ weeks gestational age (GA) or with a birth weight $(\mathrm{BW})<1500 \mathrm{~g}$ in 2016. We conducted a cross-sectional survey to evaluate the knowledge and attitudes of staff towards breast milk for preterm infants. Deficits in background knowledge and training informed a teaching programme. Education involved training sessions, development of guidelines, distribution of posters, and presentation at meetings. The first 5 infants per month born $<32$ weeks GA or BW $<1500 \mathrm{~g}$ were included in the post-intervention analysis. The effect of the interventions were evaluated using a before and after study design. Time to first MM was our key performance indicator.

Results We reviewed 123 infants born in 2016 [Median (IQR) GA 29 (26, 31) weeks, BW 1140 (820, 1410) g]. Many infants didn't start feeds in $1^{\text {st }} 24$ hours as MM was not available; median (IQR) time to 1st MM $35(17,55)$ hours, $34 \%$ of infants received $\mathrm{MM}$ in the $1^{\text {st }} 24$ hours of life. Prospective data was collected from 25 infants, born May - October 2018, following interventions [Median (IQR) GA 30 (26, 31) weeks, BW $997(890,1560) \mathrm{g}]$. The median (IQR) time to $1^{\text {st }}$ MM was $17(8,25)$ hours and $76 \%$ of infants received MM in the $1^{\text {st }} 24$ hours.

Conclusion The initial results of this hospital-wide QI initiative are promising. The median time to first $\mathrm{MM}$ has halved in the 5 months since this initiative commenced. Further PDSA cycles are indicated to ensure ongoing improvement.

\section{P151 ASSESSING THE USE OF THE ISBAR3 HANDOVER FRAMEWORK IN AN IRISH PAEDIATRIC HOSPITAL: A MEDICAL STUDENT PERSPECTIVE}

Aoife Doolan*, James Charles Shiel, Patrick Williams, Mohammad Hussain, Gearoid Corcoran, Joy Tan, Alf Nicholson. Royal College of Surgeons in Ireland, Dublin, Ireland

\subsection{6/archdischild-2019-epa.506}

Intro Medical staff are routinely educated on the $\mathrm{ISBAR}_{3}$ framework for clinical handover. This tool is implemented to encourage safer and more effective task transfer during clinical emergencies, referral to other specialties, transfer of hospital and wards. 


\section{Project aims}

1. To evaluate the use of $\mathrm{ISBAR}_{3}$ during clinical handover in a busy children's hospital

2. To increase awareness of the usage of $\mathrm{ISBAR}_{3}$ as a tool of communication among physicians and healthcare professionals.

3. To promote use of a structured handover framework amongst medical students.

Methods This is a prospective study. A team of medical students attended the morning handover meeting over a period of five weeks, and collected data on the use of $\mathrm{ISBAR}_{3}$. Points were allocated for each component of the framework that was addressed. All data was completely anonymised. The data was then compiled and analysed. We included all patients that were admitted through the Emergency Department; excluded from the dataset were all surgical patients, and patients transferred from other clinical centres.

Result A total of 39 admissions were handed over during the duration of the study. Of these, only one handover fulfilled all elements of the ISBAR3 framework. Parameters were omitted in each of the 38 other cases. The three criteria fulfilled most frequently were: Name, Age and Presenting Complaint and scoring 97\%, 89\%, 97\% respectively. The three most commonly omitted aspects were from the $\mathrm{R}_{3}$ (RISK) of the $\mathrm{ISBAR}_{3}$. This includes : Infection Control, Child Protection, Safety for Discharge, and Infection Control, scoring 10.2\%, $7.7 \%$, and $7.6 \%$, respectively.

Conclusion It is clear that the $\mathrm{ISBAR}_{3}$ tool is not being routinely utilised in handover meetings. The impact these findings have on patient care cannot be directly evaluated. Notably, 'Risk' the most commonly omitted parameter. Hence, we have identified an area of clinical practice with scope for improvement. We plan to re-audit this area, following dissemination of information, in order to complete the audit cycle.

\section{P152 IMPLEMENTATION OF A BILIRUBIN MONITORING DOCUMENT IN THE NEONATAL ICU AND POSTNATAL WARD SETTING AT UNIVERSITY MATERNITY HOSPITAL LIMERICK}

Kerrie Hennigan*, Rizwan Khan, Niazy Al-Assaf. UMHL, Limerick, Ireland

\subsection{6/archdischild-2019-epa.507}

Introduction Transcutaneous (TcB) and serum bilirubin (SBR) levels are often monitored during the neonatal period in order to decide if a newborn requires phototherapy. Other details, however, are required to assess the infant's risk factors and threshold of treatment ${ }^{1}$. Gestational age, $\mathrm{ABO} / \mathrm{Rh}$ incompatibility and Direct Coombs test (DCT) are important amongst other risk factors ${ }^{1}$ to guide our management.

Aim To improve clarity and safety when recording TcB and SBR results by creating a one-page document encompassing all necessary pieces of information.

Method Our trial bilirubin monitoring document consisted of 3 sections. The first section is a standard Phototherapy nomogram $^{1}$ followed by a section for details such as name, chart number, gestational age, date of birth, time of birth, DCT status and other risk factors. The third section consists of a table with columns for date, time of blood sample, age in hours, $\mathrm{TcB}$, SBR, risk line, risk Zone ${ }^{2}$ and plan. Moreover, we included 8 rows for continual monitoring. Three months after implementation and education of this trial document, a survey was carried out amongst midwives and neonatal nurses in UMHL. Various questions were asked regarding the clarity and safety of the new document when compared with the old way of documenting. Feedback and comments were collected and analysed.

Results 24 individuals responded to the survey. Of these, $58 \%$ found the old way of documenting 'unclear' whereas $20 \%$ found it 'very unclear'. 21\% found the new document 'clear' and the remaining 79\% found it 'very clear'. 71\% found the new document 'easy to use' and the remaining $29 \%$ found it 'very easy to use'. 33\% found the new document to be 'safer' and the remaining 67\% found it 'much safer' to use when compared with the old way of documenting. Suggestions received included creating a column for the doctor's signature next to the plan and also to include a line for the mother's blood group in the second section.

Discussion Prior to implementation of this new document, all of these details were scattered throughout the chart making it difficult for another doctor to ascertain the information when it comes to interpreting a new bilirubin result for a particular newborn. Survey response was in favour of using our new document, due to its clarity, ease of use, enhanced safety and continuity of care. We plan to consider adding the suggested changes and finalising this document as a quality improvement initiative.

\section{P153 AN AUDIT OF ADHERENCE TO NATIONAL GUIDELINES ON COMMUNICATION DURING CLINICAL HANDOVER IN THE UNIVERSITY HOSPITAL OF LIMERICK (UHL)}

Husnain Mahomed*, Peter O'Reilly, Siobhan Gallagher. University Hospital Limerick, Limerick, Ireland

\subsection{6/archdischild-2019-epa.508}

Introduction Clinical handover is defined as 'the transfer of professional responsibility and accountability for someone all aspects of care for a patient, to another person or professional group on a temporary or permanent basis.' It has been identified as a high risk step in the patients hospital journey that can lead to delay in treatment and loss of trust and confidence amongst staff and patients.

Aims To assess the quality of clinical handover in UHL PD as recommended by the Communication (Clinical Handover) in Acute and Children's Hospital Services, National Clinical Guideline No. 11 HSE (2015).

Methods A standardised proforma was used to assess the quality of our handover for all medically admitted patients in UHL PD. The audit team chose 10 randomised weekdays to collect information looking at the five aspects: suitability, patient safety, patient confidentiality, standardised communication tool (ISBAR), record keeping. A re-audit will be carried out after an education session to staff.

Results Handover was priortised over other jobs $0 \%$ of the time. Staff had accurate up to date information $20 \%$ of the time. Room was inappropriate for handover, too small, not private. Clinical protected time but not adhered to. Handover policy clear. Handover timely in $80 \%$ of cases. Handover face to face, no read back, no ISBAR, no safety pause. 8-14 interruptions (late attendance, non-urgent bleeps) 